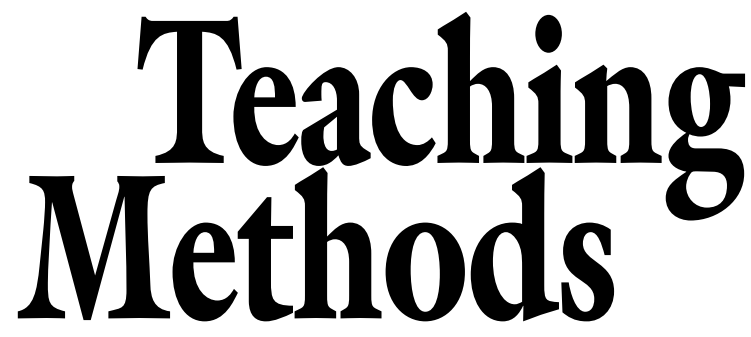

\section{An Exercise to Study the American Standard for Nursery Stock}

\author{
Ursula K. Schuch
}

ADDITIONAL INDEX WORDS. nursery production, cooperative learning

Summary. A two-part exercise was developed as part of the horticulture curriculum at Iowa State University to familiarize students with the American Standard for Nursery Stock (ASNS), and to allow them to practice and apply the ASNS with a variety of categories and types of ornamental plants. The first part of the exercise requires students to determine, according to ASNS standards, appropriate root ball/container size for plants to be moved from an existing immature landscape. During the second part, students evaluate whether root ball or container size of plants in a nursery is appropriate for the plant shoot dimensions. The exercise was designed for students to work in informal groups in a cooperative learning environment.
Department of Horticulture, Iowa State University, Ames, IA 50011. Current address: Department of Plant Sciences, University of Arizona, Tucson, AZ 85721 .

The cost of publishing this paper was defrayed in part by the payment of page charges. Under postal regulations, this paper therefore must be hereby marked advertisement solely to indicate this fact.
$\mathrm{T}$ he ASNS is a guide written for growers and buyers of nursery stock to establish a common terminology and voluntary guidelines regarding plant size and proportions (American Association of Nurserymen, 1997). In most horticulture curriculums, the ASNS is part of nursery production courses. The ASNS contains a vast amount of technical information that can be overwhelming for students unfamiliar with the different types of nursery plants and various production methods.

Traditional lecture style instruction, where knowledge is transferred from faculty to a student, is ineffective in enabling all students to comprehend, assimilate, and apply new knowledge in solving problems (Johnson et al., 1991; Thornton and Sokoloff, 1998). Learners want the subject matter to be meaningful and relevant (Jensen, 1998), but traditional lecture is the preferred learning style for only 25\% of the North American population (Kolb, 1984). Active involvement in learning activities has been shown to increase student motivation and garner a positive attitude toward learning (Johnson et al., 1991). The goal of cooperative learning is for small groups of students to work together to maximize their own and each other's learning. Cooperative learning can promote increased retention, greater intrinsic motivation and more frequent and detailed understanding, in addition to greater social competency (Johnson and Johnson, 1989).

The objective in designing this exercise was to familiarize students with the ASNS by giving them opportunities to practice and apply the standards with actual plants in two situations. The exercise, using informal, cooperative learning groups, was first implemented in the Nursery Crop Production course Hort 442 taught in the Department of Horticulture at Iowa State University. The exercise has potential application in extension and accreditation courses where learners are introduced to ASNS. Students learn about different plant types, their growth habit, how to measure plants, how to determine proper height/caliper or height/canopy relationships, and how to determine whether a root ball or container is large enough for a particular size plant. The emphasis is on ornamental plants.

Part one of the exercise requires a site with a diversity of ornamental tree and shrub species within close proximity of each other and preferably of immature age. The following plant sizes are desirable: deciduous trees with calipers up to 7 inches $(18 \mathrm{~cm})$, measured at 6 or 12 inches $(15$ or $30 \mathrm{~cm}$ ) above ground level, and heights up to $20 \mathrm{ft}(6.1 \mathrm{~m})$, deciduous shrubs up to $10 \mathrm{ft}(3.0 \mathrm{~m})$, coniferous evergreens up to $8 \mathrm{ft}(2.4 \mathrm{~m})$, and broadleaf evergreens up to $4 \mathrm{ft}(1.2 \mathrm{~m})$. Most plants of this size are suitable for digging, and subsequent ball and burlaping or containerizing, according to the ASNS. Before the exercise, the instructor tags 12 to 18 ornamental trees, shrubs and ground covers. It is desirable to include as many different categories of plants as possible, such as shade trees and flowering trees of different groups and types, deciduous shrubs of different types, upright and prostrate conifers, and different types of broadleaf evergreens. At least one plant should be tagged that exceeds height, caliper, or both of the size categories listed in the ASNS.

The first part of the exercise has a 2-h completion period, but can be extended by using a greater number and more diverse selection of plants. The instructor briefly introduces the purpose and content of ASNS to students during an 8- to 10-min presentation preceding the exercise. Students are then randomly assigned into groups of three. The instructor provides each group a copy of the ASNS, a yardstick or height pole, and a caliper, while the students bring paper and pencil to record their measurements and results. Students are encouraged to take turns in measuring, looking up information in the ASNS, recording results, and discussing results as a group. The exercise is designed for team members on 
this assignment to have defined task, role, and material interdependence, which is intended to promote each other's learning through interaction and use of social skills. All of these are important aspects of successful cooperative learning (Johnson et al., 1991). Students are also informed that each is responsible for reporting the group's results to the entire class. This element of accountability holds individuals and the group responsible for contributing (Johnson et al., 1991). Informal questions to individual students during the exercise helped the instructor gauge the level of comprehension and skill to apply the new knowledge. Formal evaluation of individual student learning followed within two to three weeks of the exercises through a written midterm.

The situation in the first part is that all of the tagged plants need to be moved, a task commonly encountered by horticulture professionals. Students then have to determine, according to ASNS, the container or box size necessary to containerize each plant or what dimension root ball is required to ball and burlap the plant. Groups are staggered, beginning with plant number one, three, five, seven, or so on, and then work consecutively through all of the plants. While students are working, the instructor observes the groups and offers assistance as necessary. Upon completing the task, the entire group walks from plant to plant, with groups taking turns reporting results. The reports include their measurements and classification of the plant, size of root ball for ball and burlap, container size, and possible corrective pruning when necessary. Each student reports on at least one plant, thus increasing participation and individual accountability. We then discuss possible discrepancies of results among groups, correct identification of plants, and implications of inaccurate height and caliper measurements. The project concludes with a summary of the correct steps to properly ball and burlap or containerize each plant.

Exceptionally large plants which do not fit the ASNS standards offer a special challenge of an open-ended problem. For these tagged plants, students suggest alternatives for root ball containment and debate which option would be most beneficial under the circumstances. In general, students agree that a larger size root ball, appro- priate to the tree's size, needs to be dug to ensure successful transplanting. Some viable alternatives which have been suggested include the construction of a box or another container of appropriate diameter and depth, digging and wrapping the root ball with burlap, or using the tree spade for transport over short distances. This concludes the first part of the exercise.

The second part of the exercise is situated in a retail or a wholesale nursery, and students determine the appropriateness of container size or root ball for each plant, the height/caliper relationship of trees, height/ canopy spread of evergreens, and height/number of canes for deciduous shrubs. Groups of three students are assigned different areas of displayed container or ball and burlap plants. Each group measures at least three species and summarizes their results to the entire class.

In closure, we briefly discuss how realistic and useful the ASNS are for consumers and the nursery industry. This part can be completed within 25 min, but can easily be expanded.

This exercise presents students with two realistic situations to practice and apply use of the ASNS, while encouraging active problem solving and cooperative learning in informal groups. Although not formally recorded, students found the group experience positive.

\section{Literature cited}

American Association of Nurserymen 1997. American standard for nursery stock. Amer. Assn. Nurserymen, Wash., D.C.

Jensen, E. 1998. Teaching with the brain in mind. Assn. for Supervision and Curriculum Development, Alex., Va.

Johnson D.W. and R.T. Johnson. 1989. Cooperation and competition. Interaction Book Co., Edina, Minn.

Johnson, D.W., R.T. Johnson, and K.A. Smith. 1991. Active learning: Cooperation in the college classroom. Interaction Book Co., Edina, Minn.

Kolb, D.A. 1984. Experiental learning: Experience as the source of learning and development. Prentice Hall, Englewood Cliffs, N.J.

Thornton, R.K. and D.R. Sokoloff. 1998. Assessing students learning of Newton's laws: The force and motion conceptual evaluation and the evaluation of active learning laboratory and lecture curricula. Amer. J. Phys. 66:338-352. 